\title{
Comparative Study of the Antioxidant and Antimicrobial Activities of Compounds Isolated from Solvent Extracts of the Roots of Securinega virosa
}

\author{
Justice D. Amenu' ${ }^{1}$ David Neglo², Daniel A. Abaye ${ }^{2 *}$ \\ ${ }^{1}$ Department of Pharmaceutical Chemistry, Faculty of Pharmacy and Pharmaceutical Sciences, \\ Kwame Nkrumah University of Science and Technology, PMB, Kumasi, Ghana \\ ${ }^{2}$ Department of Basic Sciences, School of Basic and Biomedical Sciences, University of Health and Allied Sciences, PMB 31, \\ Ho, VR, Ghana \\ Email:jdamenu@st.knust.edu.gh,d.neglo@uhas.edu.gh, ^dabaye@uhas.edu.gh
}

How to cite this paper: Amenu, J.D., Neglo, D. and Abaye, D.A. (2019) Comparative Study of the Antioxidant and Antimicrobial Activities of Compounds Isolated from Solvent Extracts of the Roots of Securinega virosa. Journal of Biosciences and Medicines, 7, 27-41.

https://doi.org/10.4236/jbm.2019.78003

Received: June 21, 2019

Accepted: August 13, 2019

Published: August 16, 2019

Copyright $\odot 2019$ by author(s) and Scientific Research Publishing Inc. This work is licensed under the Creative Commons Attribution International License (CC BY 4.0).

http://creativecommons.org/licenses/by/4.0/

(c) (i) Open Access

\begin{abstract}
There are several lines of indications on the importance of plants as accepted sources of therapeutic agents since most synthetic antioxidants and antibiotics have been associated with cytotoxicity and/or microbial resistance. In this study, the antioxidant and antimicrobial activities of a brown compound recovered from the ethanol extractable fraction (EEF) and white crystals isolated from the chloroform-methanol elution (CME) following column chromatography of the ethanolic extracts of roots of Securinega virosa were examined. Preparations from the white crystalline compound recorded greater antioxidant activity and antimicrobial activities than the crude ethanol extracts of $S$. virosa. Both the ethanol extract and the crystals showed significant antimicrobial activities against all microbes employed in this study. The crystalline compound demonstrated the highest zone of inhibition against the microbes Enterococcus faecalis with varied inhibitory activities with respect to other microorganisms. The least inhibition was against Pseudomonas fluorescens. The overall range was $8.0-22.5 \mathrm{~mm}$. The EEF of the roots of $S$. virosa recorded its highest activity against Staphylococcus aureus and Escherichia coli. There was varied inhibitory activity against other organisms; the least was against Micrococcus liteus. The zone of inhibition ranged 6.33 $17.67 \mathrm{~mm}$. Similar to the trends in susceptibility test, the EEF showed appreciable minimum inhibitory concentration (MIC), ranging from $3.13-25$ $\mathrm{mg} / \mathrm{mL}$ against test micro-organisms while the crystalline preparation had a MIC range of $1.5-25 \mathrm{mg} / \mathrm{mL}$ except against Salmonella typhii which was 50
\end{abstract}


$\mathrm{mg} / \mathrm{mL}$. Both extracts demonstrated their highest activity against $E$. faecalis reducing significantly in a dose-dependent manner by each sample against the rest of the test microbes. However, the standard broad-spectrum antibiotic, chloramphenicol, used elicited a zone of inhibition ranging from 0 - 30 $\mathrm{mm}$ but with no activity against Streptococcus thermophilus. We conclude that both the EEF and the white crystal compound isolated from the CME chromatographic fraction are potentially excellent sources of antioxidant and antimicrobial compounds.

\section{Keywords}

Securinega virosa, Root Extracts, Antioxidants, Antibiotic, Phytochemicals

\section{Introduction}

The intractable issue of antibiotic resistance is not new. The history of antibiotic discovery and use is replete with the concomitant development of antibiotic resistance. Following the discovery of penicillin by Alexander Fleming in 1928, and even before penicillin was introduced as therapeutic, a bacterial penicillinase was identified by Abraham and Chain, two of his co-workers [1]. With widespread use of penicillin in the following years, resistant strains capable of inactivating the drug became prevalent, and synthetic studies were undertaken to modify the penicillin molecule to prevent cleavage by the penicillinases ( $\beta$-lactamases) [2]. The indiscriminate use of antibiotics has exacerbated the problem. Antimicrobial resistance by pathogenic micro-organisms such as bacteria, viruses, fungi, protozoa and helminths is so widespread and costly that, it has been described as one of the biggest clinical problems currently facing humanity as it is leading to multiple-drug resistance [2] [3] [4].

Several strategies have been implemented to decrease, alleviate, or attempt to eliminate antibiotic resistance. One of these is the use of extracts from non-microbial sources, specifically, plant parts. In their natural environments, plant roots, for example, do produce metabolites that fight microbial infections [2]. The use of plant parts as medicinal products dates back to antiquity. The acceptance of traditional medicine as an alternative form of health care has led scientists to investigate the antimicrobial activity and antioxidant activities of medicinal plants [5]. Various medicinal plants have been used for years in daily life to treat disease all over the world [6]. Herbs from both natural and cultivated sources are being more widely used on a commercial scale in the food industry, in traditional medicine and for their flavouring properties [4].

Free radicals and other reactive oxygen species such as superoxide anion $\left(\mathrm{O}_{2}^{-}\right)$, hydroxyl radical $\left(\mathrm{OH}^{*-}\right)$ and hydrogen peroxide $\left(\mathrm{H}_{2} \mathrm{O}_{2}\right)$ are an entire class of highly reactive molecules derived from the normal metabolism of oxygen [7]. These molecules have been linked to many degenerative diseases such as cancer, cardiovascular disease, cataracts, immune system decline and brain dysfunction 
[8]. Recent research findings about free radicals have established that foods rich in antioxidants play a vital role in the prevention of cardiovascular diseases, cancers and neurodegenerative diseases [9]. Antioxidant compounds in foods are very essential because of their ability to reduce free radical-mediated degradation of cells and tissues in mammals.

Plant-based foods such as vegetables, legumes and whole grain cereals are known to have high contents of flavonoids, flavones, polyphenols, catechins and phytoestrogens which are antioxidants. The most common natural antioxidants are from plant sources. Examples are vitamins $\mathrm{E}$ and $\mathrm{C}, \beta$-carotene, and tannins [10]. Many scientific studies on antioxidant and antimicrobial activities of various plants have been performed and more often, emphasis has been given to essential oils or to fractions extracted in hexane, acetone, ethanol, methanol and carbon dioxide [11].

One important medicinal plant indigenous to the West African sub-region is Securinega virosa Roxb. ex. Willd Baill from the family Euphorbiaceae. It is commonly known as white berry bush, snowberry tree or simple-leaf bush weed. It is a widely used medicinal plant among the herbal medicine practitioners in West Africa including Ghana. It is associated with the treatment of a wide variety of ailments alone or in combination with other plants [12]. The local names of the plant in Ghana include "hlose, hrese, fiagbe" (Eve), "nkanaa" (Akan), "tsa" (Hausa) and "gbekebii-able-tfo" (Ga). $S$. virosa is believed to be a very important medicinal plant in Africa and is described as a true "cure all" plant; having all its parts, that is the leaves, roots, stem and fruits all used as remedies. The root is considered the most active part [12] [13]. The root extract of $S$. virosais associated with the treatment of ailments such as diabetes, diarrhoea, dysmenorrhoea, epilepsy, upper respiratory tract infections (colds and tuberculosis); renal calculus, rheumatism, tumours, gastrointestinal conditions such as stomach-ache, dysentery, intestinal worms and schistosomiasis; malaria, frigidity, arthritis and impotence [13].

The objective of this study was to employ a more structured approach and investigate the antioxidant and antimicrobial potencies of the ethanol-extractable fraction (EEF) and the crystals precipitated from chloroform-methanol extractable (CME) fraction of the root of Securinega virosa.

\section{Materials and Methods}

\subsection{Sample Collection, Identification and Preparation}

The whole plant and root samples of Securinega virosa were harvested and a herbarium specimen was prepared. The herbarium specimen was identified and authenticated at the Herbarium Section, Department of Pharmacognosy, Kwame Nkrumah University of Science and Technology (KNUST), Kumasi, Ghana and a voucher number: KNUST/HM/2017/L013 assigned. The root samples which are the subject of this investigation were cleaned, cut into smaller pieces and dried under shade for about two weeks to a constant weight and then powdered. 


\subsection{Extraction and Isolation}

One kg of the powdered plant root was weighed and subjected to soxhlet extraction in $96 \%$ ethanol for 72 hours. The ethanolic extract obtained was concentrated by removing the solvent under vacuum over a water bath at $40^{\circ} \mathrm{C}$ to give a dark brown solid. This dark brown solid was designated the ethanol extractable fraction (EEF). Twenty grams of the EEF was prepared and placed $200 \mathrm{~mL}$ capacity columns packed with silica gel of $70-230$ mesh and a gradient elution system comprising of the solvents petroleum ether, chloroform and methanol were employed. A number of fractions were collected on the basis of the eluting band colour in $100 \mathrm{~mL}$ volumes. Fractions obtained from chloroform: methanol (90:10; vol/vol) solvent were pooled and following solvent removal under vaccum, a white crystalline solid was recovered. This solid is designated as the CME fraction. The characterization and identification of the white crystalline compound is the subject of further study.

\subsection{Phytochemical Screening}

Initial screening to evaluate the presence or absence of phytochemicals or secondary metabolites of the crude extract of $S$. virosa was performed on sub-fractions according to the method described by Sasidharan et al. [14]. A summary of the protocols are in Table 1.

\subsection{Antioxidant Study}

\subsubsection{Determination of Total Polyphenol Content}

The total polyphenol content was calorimetrically estimated using Folin Ciocalteu reagent with modification [15]. Briefly, $100 \mu \mathrm{L}$ of dissolved compounds ( 5 $\mathrm{mg} / \mathrm{mL}$ each) from each extract was placed in test tubes. Five $\mathrm{mL}$ of distilled water and $0.5 \mathrm{~mL}$ of Folin Ciocalteu's reagent was added and shaken. After $5 \mathrm{mi}-$ nutes, $1.5 \mathrm{~mL}$ of $20 \%$ sodium carbonate was added and volume made up to 10 $\mathrm{mL}$ with distilled water. The mixture was allowed to incubate for 2 hours at room temperature after which an intense blue colour was developed. After incubation, absorbance was measured at $750 \mathrm{~nm}$ using a spectrophotometer (Jenway, Bibby Scientific Ltd., Stone, Staff., UK). The calibration curve was prepared using 20,40,60, 80 and $100 \mathrm{mg} / \mathrm{mL}$ solutions of gallic acid in methanol. Total phenolic contents were presented as milligrams of gallic acid (standard phenolic compound) per gram dry weight of sample (mg gallic acid/g dry weight of sample). The total phenol content of the samples was quantified and expressed as Gallic Acid Equivalent (GAE) mg/g dry weight basis (dw) and the range of a calibration curve was from 0.067 to 1.562 .

\subsubsection{DPPH Radical Scavenging Activity Assay}

Spectrophotometric Diphenylpicrylhydrazyl (DPPH) and

2,2'-Azno-bis(3-ethylbenzothiazoline-6-sulphonic acid) (ABTS) methods were used to determine the total antioxidant activity. DPPH scavenging activities of the extracts was determined with modifications [16]. The working DPPH 
Table 1. Phytochemical screening.

\begin{tabular}{|c|c|c|c|}
\hline $\begin{array}{l}\text { Secondary } \\
\text { metabolite }\end{array}$ & Name of test & Methodology & Result \\
\hline Alkaloid & Dragendorffs test & $\begin{array}{l}\text { Spot a drop of extract on a small } \\
\text { piece of pre-coated TLC plate. } \\
\text { Spray the plate with } \\
\text { Dragendorff's reagent. }\end{array}$ & Orange spot \\
\hline Glycoside & Kellar-Kiliani test & $\begin{array}{l}\text { Add } 2 \mathrm{~mL} \text { filtrate with } 1 \mathrm{~mL} \text { of } \\
\text { glacial acetic acid, } 1 \mathrm{~mL} \text { ferric } \\
\text { chloride and } 1 \mathrm{~mL} \text { concentrated } \\
\text { sulphuric acid }\end{array}$ & $\begin{array}{l}\text { Green-blue } \\
\text { coloration of } \\
\text { solution }\end{array}$ \\
\hline Tannin & Braemer's test & $\begin{array}{l}10 \% \text { alcoholic ferric chloride } \\
\text { will be added to } 2-3 \mathrm{~mL} \text { of } \\
\text { methanolic extract }(1: 1)\end{array}$ & $\begin{array}{l}\text { Dark blue or } \\
\text { greenish grey } \\
\text { coloration of the } \\
\text { solution }\end{array}$ \\
\hline Terpenoid & $\begin{array}{l}\text { Salkowski } \\
\text { test }-10 \%\end{array}$ & $\begin{array}{l}5 \mathrm{~mL} \text { extract was added with } 2 \\
\mathrm{~mL} \text { of chloroform and } 3 \mathrm{~mL} \text { of } \\
\text { concentrated sulphuric acid }\end{array}$ & $\begin{array}{l}\text { Reddish brown } \\
\text { colour of } \\
\text { interface }\end{array}$ \\
\hline Steroid & $\begin{array}{l}\text { Liebermann-Burchardt } \\
\text { test }\end{array}$ & $\begin{array}{l}\text { To } 1 \mathrm{~mL} \text { of methanolic extract, } \\
\text { add } 1 \mathrm{~mL} \text { of chloroform, } 2 \text { - } 3 \\
\mathrm{~mL} \text { of acetic anhydride, } 1 \text { to } 2 \\
\text { drops of concentrated } \\
\text { sulphuric acid. }\end{array}$ & $\begin{array}{l}\text { Dark green } \\
\text { coloration }\end{array}$ \\
\hline $\begin{array}{l}\text { Reducing } \\
\text { sugar }\end{array}$ & Fehling test Frothing & $\begin{array}{l}\text { Add } 25 \mathrm{~mL} \text { of diluted sulphuric } \\
\text { acid to } 5 \mathrm{~mL} \text { of water extract in a } \\
\text { test tube and boil for } 15 \text { mins. } \\
\text { Then cool it and neutralize with } \\
10 \% \text { sodium hydroxide to } \mathrm{pH} 7 \\
\text { and } 5 \mathrm{~mL} \text { of Fehling solution. }\end{array}$ & $\begin{array}{l}\text { Brick red } \\
\text { precipitate }\end{array}$ \\
\hline Flavonoid & Kellar-Shinoda test & $\begin{array}{l}\text { To } 2-3 \mathrm{~mL} \text { of methanolic } \\
\text { extract, add a piece of } \\
\text { magnesium ribbon and } 1 \mathrm{~mL} \text { of } \\
\text { concentrated hydrochloric acid }\end{array}$ & $\begin{array}{l}\text { Pink red or red } \\
\text { coloration of the } \\
\text { solution }\end{array}$ \\
\hline
\end{tabular}

reagent was prepared by adding $300 \mu \mathrm{L}$ of the stock $(0.6 \mathrm{mM})$ solution to 100 $\mathrm{mL}$ of methanol. Aliquots $200 \mu \mathrm{L}$ of the dissolved extracts $(\sim 5 \mathrm{mg} / \mathrm{mL}$ each) was added to $800 \mu \mathrm{L}$ of the working DPPH solution, vortexed and incubated at normal room temperature for 30 minutes. After incubation, absorbance was measured at $517 \mathrm{~nm}$ using a spectrophotometer (Jenway, Bibby Scientific Ltd., Stone, Staff., U.K.). The radical scavenging activity was calculated and expressed as percentage of the control (free radical solution minus plant extract) using Equation (1):

$$
\% \text { Scavenging }[\mathrm{DPPH}]=\left[\left(A_{0}-A_{1}\right) / A_{0}\right] \times 100
$$

where, $A_{0}$ is the absorbance of the blank (same volume of methanol) and $A_{1}$ is the absorbance in the presence of the samples or standard. 


\subsubsection{Determination of 2,2'-Azino-Bis(3-Ethylbenzthiazoline-6-Sulphonic) Acid (ABTS) Scavenging Activity}

The ABTS scavenging activity was determined as described by Re et al. [17] with modification. Briefly, a stock solution of $7 \mathrm{mM}, 10 \mathrm{~mL}$ ABTS and $2.4 \mathrm{mM}, 10 \mathrm{~mL}$ potassium persulfate were prepared in distilled water and mixed in order to generate the ABTS free radical $\left(\mathrm{ABTS}^{*+}\right)$. The resulting solution was incubated in the dark at room temperature for $12 \mathrm{hr}$ until the reaction was completed, by the observation of a constant absorbance. An aliquot of the ABTS solution (1 $\mathrm{mL}$ ) was further diluted in $50 \mathrm{~mL}$ of methanol and the absorbance calibrated to 0.7 at $734 \mathrm{~nm}$. Aliquots $(20 \mu \mathrm{L})$ of different concentrations of the extracts and standard (prepared from a stock solution of $1 \mathrm{mg} / \mathrm{mL}$ in methanol) was added to $1 \mathrm{~mL}$ of the $\mathrm{ABTS}^{*}$ solution, mixed and incubated at $30^{\circ} \mathrm{C}$ for $10 \mathrm{~min}$. The absorbance was read at $734 \mathrm{~nm}$. The radical scavenging capacity was compared with that of ascorbic acid and the inhibition was calculated as percentage of the control sample (free radical solution minus plant extract) as expressed in Equation (2):

$$
\% \text { Inhibition }=\left[\left(A_{\text {control }}-A_{\text {sample }}\right) / A_{\text {control }}\right] \times 100
$$

where, $A_{\text {control }}$ is the absorbance of $\mathrm{ABTS}^{*+}$ solution and $A_{\text {sample }}$ is the absorbance of $\mathrm{ABTS}^{*+}$ and sample (extract + standard).

\subsection{Antimicrobial Evaluation}

\subsubsection{Susceptibility Test}

The following clinically relevant microorganisms, Enterococcus faecalis ATCC 19433, Salmonella typhii ATCC 19430, Staphylococcus albus, Escherichia coli 25922, Bacillus subtilis NCTC 10073, Klebsiella oxytoca ATCC 13182, Micrococcus liteus, Shigella sonnei DSM 5570, were used in the study. The following strains were included; Listeria innocua, Pseudomonas fluorescens, Staphylococcus aureus NCIMB 6571, Salmonella enterica ATCC 13076, and Streptococcus thermophilus DSM 20617. All microbial strains were obtained from the Microbiology Laboratory, School of Basic and Biomedical Sciences, UHAS and standardized to 0.5 McFarland standard according to EUCAST using a spectrophotometer (Jenway, Bibby Scientific Ltd., Stone, Staff., U.K.) and were properly labelled for the experiments.

\subsubsection{Disc Diffusion Method}

The antimicrobial activity of the extracts was determined using both the Kirby-Bauer agar disc diffusion method and the broth dilution method with micro-dilution method [18]. About $20 \mathrm{~mL}$ of nutrient agar was dispensed into individual Petri dishes and allowed to solidify. One loop of each strain taken from each working stock was incubated on a nutrient agar at $37^{\circ} \mathrm{C}$ for $18-24$ hrs. Bacterial strain cultures were adjusted to obtain a final concentration of $10^{8}$ $\mathrm{CFU} / \mathrm{mL}$ using a $0.5 \mathrm{McF}$ arland standard. A sterile cotton swab was then dipped into the adjusted inoculum suspension and then swabbed on a plate by 
three-way method allowing it to stand for 15 mins. Wells (4 $\mathrm{mm}$ diameter) were cut into the agar plates using a sterile cork borer (No. 3). Aliquots $(30 \mu \mathrm{L})$ of the various extracts at concentration of $40 \mathrm{mg} / \mathrm{mL}$ were dispensed into the individual wells. Chloramphenicol antibiotic at a final concentration of $30 \mu \mathrm{g} / \mathrm{mL}$ was used as a control standard at the middle of each plate. The agar well plates were then incubated for $18-24 \mathrm{hr}$ at $35^{\circ} \mathrm{C} \pm 2{ }^{\circ} \mathrm{C}$. The antibacterial activity against each test organism was quantified by determining mean zone of growth inhibition. The procedure was done in triplicate and the mean zones of inhibition recorded.

\subsubsection{Broth Dilution Method}

The minimum inhibitory concentrations (MIC) of the recovered compounds, EEF and CME, on the isolates of the various organisms were determined using the micro-dilution method [18]. Aliquots $(200 \mu \mathrm{L})$ from stock solutions (200 $\mathrm{mg} / \mathrm{mL}$ ) of each extract were dispensed in Eppendorf tubes and then $200 \mu \mathrm{L}$ of Muller Hinton Broth added. The preparations were then serially diluted to obtain concentrations ranging from 0.39 to $100 \mathrm{mg} / \mathrm{mL}$.

The zero concentration $(0 \mathrm{mg} / \mathrm{mL})$ tube served as a growth control. The inoculum size was prepared by diluting cell cultures in saline to obtain a cell concentration of $108 \mathrm{CFU} / \mathrm{mL}$ using $0.5 \mathrm{McFarland}$ standards and then diluted again with saline to obtain a cell concentration of $106 \mathrm{CFU} / \mathrm{mL}$. Aliquots $(10 \mu \mathrm{L})$ of each standard inoculum were added to the diluted solutions of various concentrations. Cultivation was carried out at $35^{\circ} \mathrm{C} \pm 2^{\circ} \mathrm{C}$ for $18-20 \mathrm{hr}$. Presence of bacterial growth was determined by the addition of $20 \mu \mathrm{L}(0.2 \mathrm{mg} / \mathrm{mL})$ of 3-(4,5-dimethylthiazole-2-yl)-2,5-diphenyltetrazolium bromide (MTT). The MIC is regarded as the lowest concentration of the extract that did not permit the growth of any of the test bacteria after the period of incubation [19]. This was indicated by the absence of purple colouration upon the addition of the reagent MTT.

\section{Results}

The results of the phytochemical analysis of the EEF from the root are summarized in Table 2. Present were glycosides, saponins, tannins, alkaloids, flavonoids, coumarins and the reducing sugars.

\section{Antioxidant Activity}

The antioxidant activity of the brown compound from ethanol extracts (EEF) and the white crystals recovered from the chloroform-methanol eluted (CME) from column chromatography were determined and compared with the activity of ascorbic acid. The antioxidant activity is presented in Table 3.

Plants are very good sources of antioxidants and it has been suggested that the potential of phytochemicals in the treatment of many diseases may lie in their antioxidant effects [20]. The data showed that the white crystalline compound (CME) exhibited very good antioxidant activity and resulted in $53.5 \%$ microbial 
Table 2. Phytochemical analysis.

\begin{tabular}{cc}
\hline Phytochemical & Presence \\
Glycosides & + \\
Saponins & + \\
Tannins & + \\
Alkaloids & + \\
Flavonoids & + \\
Coumarins & - \\
Sterols & - \\
Triterpenoids & + \\
Free reducing sugars & + \\
\hline
\end{tabular}

(+) positive. (-) negative.

Table 3. Results for antioxidant activity.

\begin{tabular}{cccc}
\hline \multirow{2}{*}{$\begin{array}{c}\text { Concentration } \\
(\mathrm{mg} / \mathrm{mL})\end{array}$} & Ascorbic acid & CME & EEF \\
\cline { 2 - 4 } 0.10 & $65.0 \pm 0.500$ & $53.5 \pm 0.500$ & $26.4 \pm 0.549$ \\
0.25 & $69.7 \pm 0.577$ & $58.7 \pm 0.764$ & $27.8 \pm 0.608$ \\
0.50 & $73.2 \pm 0.764$ & $62.3 \pm 0.577$ & $31.5 \pm 0.516$ \\
1.00 & $74.5 \pm 0.500$ & $64.7 \pm 0.289$ & $35.2 \pm 0.435$ \\
5.00 & $94.0 \pm 0.685$ & $82.1 \pm 0.582$ & $25.0 \pm 0.575$ \\
\hline
\end{tabular}

$\mathrm{EEF}=$ brown compound recovered from ethanol-extractable fraction, $\mathrm{CME}=$ white crystalline compound extracted from chloroform-methanol solvent following column chromatography. Each value is the mean of three replicate experiments \pm SD.

inhibition at a concentration of $0.1 \mathrm{mg} / \mathrm{mL}$ and increasing to $82 \%$ inhibition at a concentration of $5 \mathrm{mg} / \mathrm{mL}$. The brown compound (EEF) also exhibited good antioxidant properties. At 0.1 to $1 \mathrm{mg} / \mathrm{mL}$ concentration, inhibition was 25.4 to $35.2 \%$. Proton $\left(\mathrm{H}^{*+}\right)$ radical scavenging is a principal attribute of antioxidants. ABTS $^{*+}$ is a protonated free radical with an extreme absorbance at $734 \mathrm{~nm}$, which drops on scavenging by antioxidants. The recovered compounds were noted to reduce the radicals in a concentration-dependent manner. There results, therefore, showed that both the CME and EEF compounds are promising sources of free radical scavengers. Both compounds contained good quantities of total phenolics and good antioxidant activity by DPPH in vitro at the concentration of $5 \mathrm{mg} / \mathrm{mL}$ (Table 4 ).

The two compounds, EEF and CME, at $40 \mathrm{mg} / \mathrm{mL}$ concentration, showed significant antimicrobial activities against all strains of microbes used in this experiment (Table 5). The CME crystalline compound recorded the greater activity, in particular against $E$. faecalis, $M$. liteus, and $S$. enterica in the disc diffusion assay. The compounds were evaluated against the antibiotic chloramphenicol at a concentration of $30 \mu \mathrm{g} / \mathrm{mL}$. 
Table 4. Estimation of total phenolics and DPPH.

\begin{tabular}{ccc}
\hline Sample/Fraction & Total Phenolics/(mg GAE/g) & DPPH-Concentration (\%) \\
\hline EEF & $42.49 \pm 1.216$ & $44.54 \pm 8.528$ \\
CME & $75.07 \pm 0.127$ & $27.46 \pm 5.515$ \\
\hline
\end{tabular}

$\mathrm{EEF}=$ brown compound recovered from ethanol-extractable fraction, $\mathrm{CME}=$ white crystalline compound extracted from chloroform-methanol solvent following column chromatography. Each value is the mean of three replicate experiments \pm SD.

Table 5. Zone of inhibition of compound recovered from the ethanol-fraction and chloroform-methanol chromatographically eluted compounds from the roots of $S$. virosa against the test micro-organisms by the Kirby-Bauer agar disc diffusion method.

\begin{tabular}{lccc}
\hline \multirow{1}{*}{ Strains } & \multicolumn{3}{c}{ Mean zone of inhibition (mm) } \\
\cline { 2 - 4 } & $\begin{array}{c}\text { Chloramphenicol } \\
\text { (Control) } /(30 \mu \mathrm{g} / \mathrm{mL})\end{array}$ & $\begin{array}{c}\mathrm{EEF}(\mathbf{4 0} \\
\mathrm{mg} / \mathrm{mL})\end{array}$ & $\begin{array}{c}\text { CME }(40 \\
\mathrm{mg} / \mathrm{mL})\end{array}$ \\
\hline S. albus & $18.67 \pm 0.58$ & $12.5 \pm 0.50$ & $16.5 \pm 0.50$ \\
S. aureus (NCIMB 6571) & $20.13 \pm 0.06$ & $17.67 \pm 0.42$ & $21 \pm 0.30$ \\
E. faecalis (ATCC 19433) & $17.5 \pm 0.50$ & $16 \pm 0.00$ & $22.5 \pm 0.50$ \\
Pseudomonas fluorescens & $9.5 \pm 0.50$ & $16.5 \pm 0.50$ & $8 \pm 0.00$ \\
E. coli (ATCC 25922) & $19.5 \pm 0.50$ & $17.5 \pm 0.50$ & $8.5 \pm 0.50$ \\
B. subtilis & $23 \pm 1.00$ & $17.33 \pm 0.58$ & $20.5 \pm 0.50$ \\
Micrococcus liteus & $14 \pm 1.00$ & $6.33 \pm 1.53$ & $12.33 \pm 1.53$ \\
Listeria innocua & $30.67 \pm 2.08$ & $14 \pm 0.50$ & $15.33 \pm 0.76$ \\
K. oxytoca (ATCC 13182) & $29 \pm 2.65$ & $15.5 \pm 0.50$ & $14.67 \pm 0.76$ \\
S. enterica (ATCC 13076) & $22.33 \pm 0.58$ & $8.43 \pm 0.12$ & $21.33 \pm 0.58$ \\
Shigella Sonnei (DSM 5570) & $23 \pm 2.65$ & $8.5 \pm 0.50$ & $17.17 \pm 0.76$ \\
S. thermophiles DSM 20617 & $\mathrm{ND}$ & $12.5 \pm 0.50$ & $17.5 \pm 0.50$ \\
S. typhi & $29.33 \pm 1.53$ & $13.5 \pm 0.50$ & $8.5 \pm 0.50$ \\
\hline
\end{tabular}

$\mathrm{EEF}=$ brown compound recovered from ethanol-extractable fraction, $\mathrm{CME}=$ white crystalline compound recovered from chloroform-methanol solvent following column chromatography, NA = No Activity. Each value is the mean of two replicates $\pm \mathrm{SD}$.

In the broth dilution assay, the microbes in the inoculums were significantly reduced in a dose-dependent manner by both EEF and CME compounds (Table 6). The trend of activity was similar to the disc diffusion method with slight differences.

\section{Discussion}

Antioxidants are known to be the first line of defense against damages caused by free radicals. Therefore, antioxidants which are contained in some plant parts are necessary for the maintenance of good health [21]. In view of this, the antioxidant activity of brown compound recovered from the ethanol extract (EEF) and white crystalline compound recovered from the chloroform-methanol chromatographic elution (CME) from the roots of $S$. virosa were investigated 
Table 6. Minimum inhibitory concentration of ethanol and chloroform-methanolextractable compounds of the roots of $S$. virosa against the test organisms by the broth dilution method.

\begin{tabular}{lcc}
\hline \multirow{2}{*}{ Microbial Strain } & \multicolumn{2}{c}{ Minimum inhibitory concentration $\mathbf{~ g} / \mathrm{mL}$} \\
\cline { 2 - 3 } & EEF & CME \\
\hline S. albus & 25.00 & 12.50 \\
S. aureus (NCIMB 6571) & 25.00 & 12.50 \\
E. faecalis (ATCC 19433) & 3.13 & 1.56 \\
P. fluorescens & 25.00 & 12.50 \\
E. coli (ATCC 25922) & 12.50 & 25.00 \\
B. subtilis & 25.00 & 12.50 \\
M. Iiteus & 3.13 & 3.13 \\
L. innocua & 25.00 & 25.00 \\
K. oxytoca (ATCC 13182) & 6.25 & 6.25 \\
S. enterica (ATCC 13076) & 12.50 & 1.56 \\
S. sonnei (DSM 5570) & 25.00 & 3.13 \\
S. thermophilus (DSM 20617) & 25.00 & 6.25 \\
S. typhii & 25.00 & 50.00 \\
\hline
\end{tabular}

$\mathrm{EEF}=$ brown compound recovered from ethanol-extractable fraction, $\mathrm{CME}=$ white crystalline compound recovered from chloroform-methanol solvent following column chromatography.

using $\mathrm{ABTS}^{*+}$ decolorization and DPPH activity. This was followed by the estimation of the total phenolic content. $\mathrm{ABTS}^{*+}$ has an attribute of scavenging radical proton $\left(\mathrm{H}^{*+}\right)$ with a maximum absorbance at $734 \mathrm{~nm}$ which decreases on scavenging by antioxidants. The two recovered compounds from roots of $S$. virosa were observed to quench the radicals in a concentration-dependent pattern giving results which indicate that these are promising free radicals scavengers. In plants, aside vitamin $\mathrm{C}$ showing the highest antioxidant property, here, the white CME compound has been shown to be a potent antioxidant. Similarly, DPPH also widely used for screening antioxidant activity is a nitrogen-centered free radical and sensitive for active compound detection at low concentrations hence any compound capable of scavenging significant amount of DPPH may be useful in reducing the level of other reactive nitrogen species in living cells [22]. From the result, at concentration of $5 \mathrm{mg} / \mathrm{mL}$, the ethanol-extractable brown EEF compound from the roots of $S$. virosa showed a more scavenging activity than the white precipitate crystalline compound CME.

Phenolic compounds are found to be responsible for the antioxidant actions in plants as a result of their high tendency to chelate metals, especially iron and copper [23]. This attribute is due to these compounds possessing hydroxyl groups in their structure which have high affinity to chelate the metallic species. The presence of these phenolic compounds in these extracts would potentially offer the protection of cells against oxidative damage than using drugs with unconnected effects. From the results, the total phenolic content of the white crys- 
talline compound was greater than that of the brown compound from the ethanolic fraction. We reasoned that both fractions contain many such compounds, acting synergistically as antioxidants. The greater phenolic effect is most likely due to the fact that the white compound (CME) is of a greater concentration as it was further isolated following column chromatography of the EEF.

Other important compounds present in plants of medical importance are phytochemicals, most of which have been demonstrated to possess many health beneficial activities including antimicrobial activities. They constitute antibiotic principals of plants and are found to be distributed in plants including leaves of Lantana camara [24]. The presence of these phytochemicals has been associated with the antibacterial activity of extract hence the extract that contains them in higher amount are considered to be superior in their antimicrobial activity [6]. On the whole, the white crystalline compound demonstrated greater antimicrobial activity than the brown ethanol extract (Table 6).

The medicinal properties of various parts of $S$. virosa have been reported: sleep-inducing effects (in mice) of bergenin isolated from the butanol extractable fraction of the roots [25]; psychopharmacological activities of methanol extracts from the leaves [26]; anti-tumour cell growth and proliferation (in mice) using methanol extracts from the roots [27]. Here, we assume reasonably that, the white crystalline compound isolated from the ethanol extract via elution on column chromatography, considering the antioxidant activity of the compound, and also the phytochemical evaluation tested positive for glycosides, is most likely bergenin, however, that is a subject for further characterization and identification.

In this study, we evaluated the antioxidant and antibiotic activities of the brown compound from the ethanol extractable fraction and white crystals precipitated from the chloroform-methanol (90:10; vol/vol) solvent fraction obtained from column chromatography of the aliquots of the original ethanolic root extract of $S$. virosa. Both compounds were found to have antibacterial activity against all the test organisms and the activities of each were augmented with increasing concentrations. The white crystalline compound recovered from the chloroform-methanol fraction exhibited a greater antibacterial activity than the brown ethanolic extract (Table 3). The presence of zones of inhibition when preparations of the two compounds were used in susceptibility assay is an indication of its antimicrobial activity (Table 5, Table 6 and Figure 1). The trend in the susceptibility test of the white crystalline compound demonstrated the highest zone of inhibition against Enterococcus faecalis and other varied inhibitory activities in respect to other micro-organisms. The least inhibition was against Pseudomonas fluorescens; the overall range $8.0-22.5 \mathrm{~mm}$. The brown ethanol extract of the roots of $S$. virosa recorded its highest activity against Staphylococcus aureus and Escherichia coli with varied inhibitory activities against other organisms. The least inhibition was against Micrococcus liteus. The zone of inhibition ranged 6.33 - $17.67 \mathrm{~mm}$. Similar to the above trends, the brown compound 


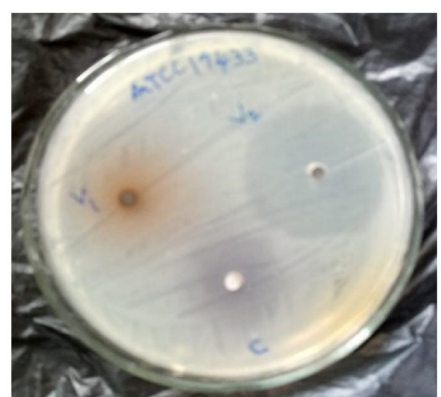

E. faecalis (ATCC 19433)

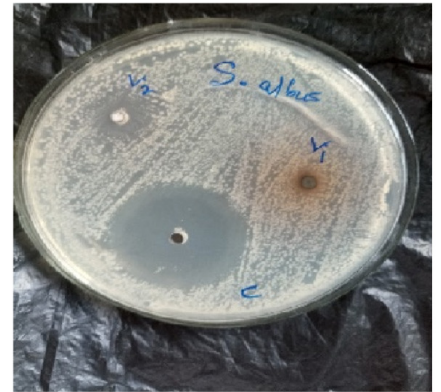

S. albus

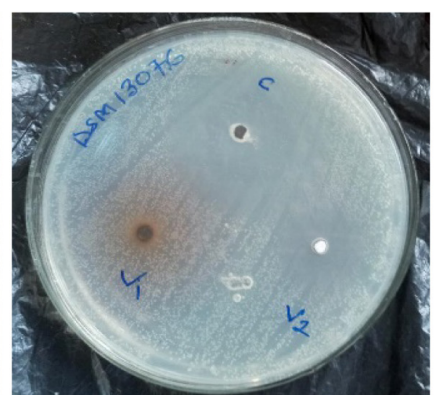

S. enterica (DSM13076)

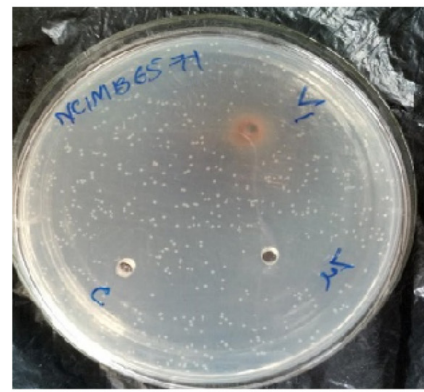

S. aureus (NCIMB 6571)

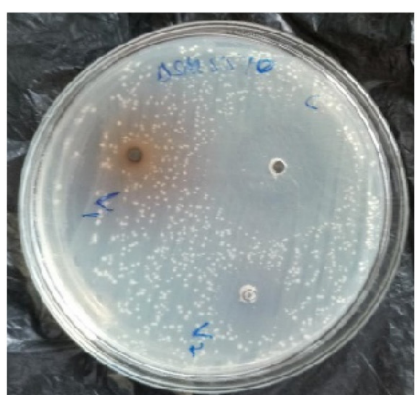

S. sonnei (DSM 5570)

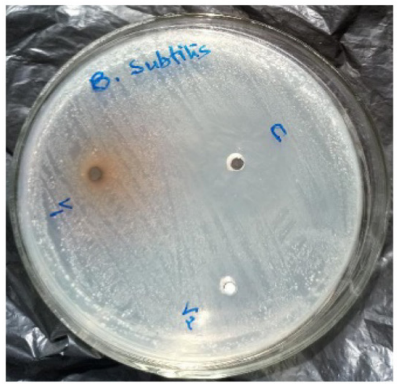

B. subtilis

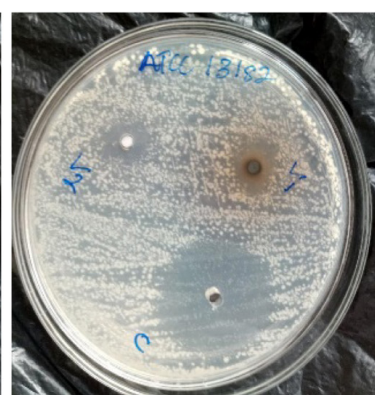

K. oxytoca (DSM 13182)

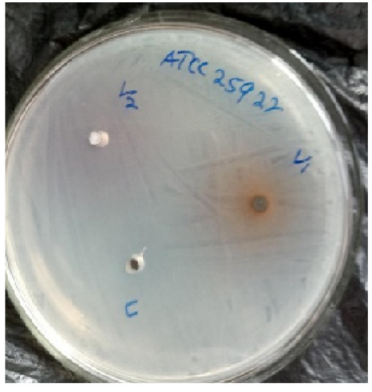

E. coli (ATCC 25922)

Figure 1. Plates showing zones of inhibition of the brown ethanol extracted (EEF; $\mathrm{V}_{1}$ ) and the chloroform-methanol column chromatography eluted crystalline $\left(\mathrm{CME} ; \mathrm{V}_{2}\right)$ compounds, and the antibiotic chloramphenicol against selected clinically relevant microbial strains by the Kirby-Bauer agar disc diffusion method.

from the ethanol extract showed appreciable MIC of range $3.13-25 \mathrm{mg} / \mathrm{mL}$ against test the micro-organisms while white crystalline compound recorded the MIC range of 1.5 - $25 \mathrm{mg} / \mathrm{mL}$, except with $S$. typhii which was $50 \mathrm{mg} / \mathrm{mL}$.

In the broth dilution assay, $E$. faecalis and $S$. enterica were highly susceptible to the white crystalline compound. Susceptibility decreased for $M$. liteus and $E$. coli then $K$. oxytoca and $S$. thermophiles, with $S$. typhii being least susceptible. The assay from the brown compound showed that, E. faecalis and M. liteus were the most susceptible followed by $K$. oxytoca, then $S$. enterica, and $E$. coli with the rest being least susceptible. Also similar to the trends in broth dilution, the preparations of the white crystals showed the largest zone of inhibition against $E$. faecalis followed by $S$. enterica with the least being $P$. fluorescens. The brown compound showed the highest zone of inhibition against $E$. coli and $S$. aureus followed by $B$. subtilis with the least being $M$. liteus. Also the standard, broad-spectrum antibiotic, chloramphenicol, used elicited a zone of inhibition ranging from $0-30 \mathrm{~mm}$ with no activity against $S$. thermophiles. Our findings indicate that the ethanol extractable brown compound and white crystalline compound precipitated following column chromatography in chloroform-methanol, are potent antibacterial agents in this context. The observations of the crude ethanol root extract and the crystalline compound inhibiting the growth of microbes, including clinically relevant strains, was in a manner dependent on concentration in the broth and has proven to be better than some activities exhibited by the conventional antibiotics. Hence, studies connected with the activities of this plant against infectious agents should be embraced with enthusiasm. 
The purification, characterization and identity of the white crystalline compound together with its antibiotic principle are the subject of another study.

\section{Conclusion}

The results of the present study reveal that, from the roots of $S$. virosa, the brown compound yielded from ethanol-extractable fraction and the white crystalline compound precipitated from the chloroform-methanol fraction, the latter, which was then subjected to chromatographic isolation, possess significant antioxidant and antimicrobial activities. The white crystalline solid was the more active compound. Both preparations were the most effective against $E$. faecalis, a clinically relevant strain, with varying activity against others and least effective against to S. typhii. Likewise, the standard broad-spectrum antibiotic (chloramphenicol) used, elicited zone of inhibition ranging from $0-30 \mathrm{~mm}$ with no activity against $S$. thermophiles. Hence, both isolated compounds are, therefore, presented as capable candidates for the production of unique anti-oxidative and anti-infectious agents. Also, from the phytochemical analysis and antibacterial activity, these test samples support the use of the root extract of $S$. virosa in ethno-medicine and could serve as a potential source for pharmaceutical formulations against some pathogenic microorganisms. Further tests and optimisation processes against more clinically relevant microbial strains are required.

\section{Acknowledgements}

The authors would like to thank by Mr. C. Osafo Asare of the Herbarium Section, Department of Pharmacognosy, KNUST, Kumasi, Ghana, who identified and authenticated the $S$. virosa specimens, and Dr. Clement O. Tettey, Department of Biomedical Science, UHAS, Ho, for providing the microbial strains.

\section{Conflicts of Interest}

Authors have declared that no competing interests exist.

\section{Authors' Contributions}

The idea was developed by JDA and DN. Experiments were designed, performed, and data were collected and analysed by all three authors. All authors contributed to manuscript writing. All authors approve the final manuscript.

\section{Additional Information}

The raw data for this study are available upon request.

\section{Funding}

This was a self-funded study, with all authors contributing.

\section{References}

[1] Abraham, E.P. and Chain, E. (1940) An Enzyme from Bacteria Able to Destroy Pe- 
nicillin. Reviews of Infectious Diseases, 10, 677-678.

http://www.ncbi.nlm.nih.gov/pubmed/3055168

[2] Davies, J. and Davies, D. (2010) Origins and Evolution of Antibiotic Resistance. Microbiology and Molecular Biology Reviews, 74, 1092-2172.

https://www.ncbi.nlm.nih.gov/pmc/articles/PMC2937522

https://doi.org/10.1128/MMBR.00016-10

[3] Levy, S.B. and Marshall, B. (2004) Antibacterial Resistance Worldwide: Causes, Challenges and Responses. Nature Medicine Supplement, 10, 122-129.

https://www.ncbi.nlm.nih.gov/pubmed/15577930 https://doi.org/10.1038/nm1145

[4] Adu, F., Boakye, Y.D., Agyare, C., Sam, G.H., Etsiapa, V. and Osei, F.B. (2019) Antibacterial Resistance Modulatory Properties of Selected Medicinal Plants from Ghana. African Journal of Pharmacy and Pharmacology, 13, 57-69.

https://doi.org/10.5897/AJPP2019.4989

[5] Nostro, A., Germano, M.P., Angelo, V.D., Marino, A. and Cannatelli, M.A. (2000) Extraction Methods and Bioautography for Evaluation of Medicinal Plant Antimicrobial Activity. Letters in Applied Microbiology, 30, 379-384.

https://www.ncbi.nlm.nih.gov/pubmed/10792667

https://doi.org/10.1046/j.1472-765x.2000.00731.x

[6] Rauha, J.-P., Remes, S., Heinonen, M., Hopia, A., Kahkonen, M., Kujala, T., Pihlaja, K., Vuorela, H. and Vuorela, P. (2000) Antimicrobial Effects of Finnish Plant Extracts Containing Flavonoids and Other Phenolic Compounds. International Journal of Food Microbiology, 56, 3-12. https://doi.org/10.1016/S0168-1605(00)00218-X

[7] Nurul, S.R. and Asmah, R. (2012) Evaluation of Antioxidant Properties in Fresh and Pickled Papaya. International Food Research Journal, 19, 1117-1124.

[8] Nimse, S.B. and Pal, D. (2015) Free Radicals, Natural Antioxidants, and Their Reaction Mechanisms. RSC Advances, 5, 27986-28006. https://doi.org/10.1039/C4RA13315C

[9] Sivanandham, K.P.A. and Alagarsamy, S. (2014) Natural Antioxidants and Its Benefits. International Journal of Food and Nutritional Science, 3, 1-39.

[10] Dasgupta, A. and Klein, K. (2014) Antioxidant Vitamins and Minerals. In: Dasgupta, A. and Klein, K., Eds., Antioxidants in Food, Vitamins and Supplements. Prevention and Treatment of Disease, Elsevier, Amsterdam, 277-294. https://doi.org/10.1016/B978-0-12-405872-9.00015-X

[11] Albayrak, S., Aksoy, A., Sagdic, O. and Albayrak, S. (2012) Antioxidant and Antimicrobial Activities of Different Extracts of Some Medicinal Herbs Consumed as Tea and Spices in Turkey Extracts of Some Medicinal Herbs Consumed as Tea. Journal of Food Biochemistry, 36, 547-554. https://doi.org/10.1111/j.1745-4514.2011.00568.x

[12] Tabuti, J.R.S. (2007) Flueggea virosa (Roxb. ex Willd.) Voigt. In: Schmelzer, G.H. and Gurib-Fakim, A., Eds., PROTA (Plant Resources of Tropical Africa), PROTA Foundation, Wageningen, 1.

http://database.prota.org/PROTAhtml/Flueggea\%20virosa_En.htm

[13] Magaji, M.G., Yaro, A.H., Mohammed, A., Zezi, A.U., Tanko, Y. and Bala, T.Y. (2007) Preliminary Antidiarrhoeal Activity of Methanolic Extracts of Securinega virosa (Euphorbiaceae). African Journal of Biotechnology, 6, 2752-2757. https://doi.org/10.5897/AJB2007.000-2440

[14] Sasidharan, S., Chen, Y., Saravanan, D., Sundram, K.M. and Latha, L.Y. (2011) Extraction, Isolation and Characterization of Bioactive Compounds from Plants' Ex- 
tracts Institute for Research in Molecular Medicine (INFORM), Universiti Sains Malaysia, Minden 11800. African Journal of Traditional, Complementary and Alternative Medicine, 8, 1-10. https://doi.org/10.1016/j.jpba.2005.01.021

[15] Bhalodia, N.R. and Shukla, V.J. (2011) Antibacterial and Antifungal Activities from Leaf Extracts of Cassia fistula L.: An Ethnomedicinal Plant. Journal of Advanced Pharmaceutical Technology and Research, 2, 104-109. https://doi.org/10.4103/2231-4040.82956

[16] Awah, F.M. and Verla, A.W. (2010) Antioxidant Activity, Nitric Oxide Scavenging Activity and Phenolic Contents of Ocimum gratissimum Leaf Extract. Journal of Medicinal Plants Research, 4, 2479-2487. https://doi.org/10.5897/JMPR10.262

[17] Re, R., Pellegrini, N., Proteggente, A., Pannala, A., Yang, M. and Rice-Evans, C. (1999) Antioxidant Activity Applying an Improved ABTS Radical Cation Decolorization Assay. Free Radical Biology and Medicine, 26, 1231-1237. https://doi.org/10.1016/S0891-5849(98)00315-3

[18] Eloff, J.N. (1998) A Sensitive and Quick Microplate Method to Determine the Minimal Inhibitory Concentration of Plant Extracts for Bacteria. Planta Medica, 64, 711-713. https://doi.org/10.1055/s-2006-957563

[19] Andrews, J.M. (2001) Determination of Minimum Inhibitory Concentrations. Journal of Antimicrobial Chemotherapy, 48, 5-16. https://doi.org/10.1093/jac/dkf083

[20] Akinmoladun, A.C., Ibukun, E.O., Afor, E., Obuotor, E.M. and Farombi, E.O. (2007) Phytochemical Constituent and Antioxidant Activity of Extract from the Leaves of Ocimum gratissimum. Scientific Research and Essay, 2, 163-166. https://www.researchgate.net/publication/228352140

[21] Vivekananthan, D.P., Penn, M.S., Sapp, S.K., Hsu, A. and Topol, E.J. (2003) Use of Antioxidant Vitamins for the Prevention of Cardiovascular Disease: Meta-Analysis of Randomised Trials. The Lancet, 361, 2017-2023. https://doi.org/10.1016/S0140-6736(03)13637-9

[22] Rao, A.S.V.C., Reddy, S.G., Babu, P.P. and Reddy, A.R. (2010) The Antioxidant and Antiproliferative Activities of Methanolic Extracts from Njavara Rice Bran. BMC Complementary and Alternative Medicine, 10, 4. https://doi.org/10.1186/1472-6882-10-4

[23] Young, I.S. (2001) Measurement of Total Antioxidant Capacity. Journal of Clinical Pathology, 54, 356-361. https://doi.org/10.1136/jcp.54.5.339

[24] Naz, R. and Bano, A. (2013) Phytochemical Screening, Antioxidants and Antimicrobial Potential of Lantana camara in Different Solvents. Asian Pacific Journal of Tropical Disease, 3, 480-486. https://doi.org/10.1016/S2222-1808(13)60104-8

[25] Magaji, M.G., Anuka, J.A., Abdu-Aguye, I., Yaro, A.H. and Hussaini, I.M. (2008) Behavioural Effects of the Methanolic Root Bark Extract of Securinega Virosa in Rodents. African Journal of Traditional, Complement and Alternative Medicine, 5, 147-153. https://doi.org/10.4314/ajtcam.v5i2.31266

[26] Magaji, M.G., Yakubu, Y., Magaji, R.A., Musa, A.M., Yaro, A.H. and Hussaini, I.M. (2014) Psychopharmacological Potentials of Methanol Leaf Extract of Securinega virosa Roxb (Ex Willd) Baill. in Mice. Pakistan Journal of Biological Sciences, 17, 855-859. https://doi.org/10.3923/pjbs.2014.855.859

[27] Magaji, M.G., Jamilu, Y., Muhammad, M.A., Akpojo, A.J., Abdu-Aguye, I. and Hussaini, I.M. (2015) Securinega virosa (Euphorbiaceae) Root Bark Extract Inhibits Glioblastoma Multiforme Cell Survival in Vitro. African Journal of Pharmacy and Pharmacology, 9, 684-693. https://doi.org/10.5897/AJPP2014.4221 